\title{
Unhealthy and Present: Motives and Consequences of the Act of Presenteeism Among Taiwanese Employees
}

\author{
Luo Lu and Hui Yen Lin \\ National Taiwan University
}

\author{
Cary L. Cooper \\ Lancaster University
}

\begin{abstract}
The aim of this study was twofold: first, to delineate the underlying motives of the act of presenteeism and develop suitable measures for both the motives and the behavioral manifestation of the act; second, to systematically examine work and health consequences of the act of presenteeism in a Chinese work context. Using structured questionnaires, we employed a 2-wave panel study design in which antecedents, motives, and consequences of the act of presenteeism were measured in a diverse sample of 245 full-time Chinese employees in Taiwan. Hierarchical regression analyses showed that self-efficacy and neuroticism were significantly associated with approach and avoidance motives for the act of presenteeism, respectively. Moreover, analyzing the panel data with fixed effects specifications, we found that the act of presenteeism was negatively associated with employees' physical health, mental health, and job satisfaction, whereas it was positively associated with exhaustion. In conclusion, the present study shed some light on motives, behavioral manifestations, antecedents, and consequences of the act of presenteeism to extend the existing literature.
\end{abstract}

Keywords: presenteeism, self-efficacy, neuroticism, individual consequences

Following the global economic recession, a significant number of organizations have conducted downsizing or reengineering, attempting to do more with less. The work environment has thus changed dramatically, and arguably may have increased the prevalence of presenteeism from associated rise in job insecurity. Presenteeism refers to attending work while ill, or succinctly put, "unhealthy and present" (Robertson \& Cooper, 2011). As organizations attempt to keep a lean workforce to reduce the operating cost, employees are less likely to find job replacement when considering sick leave. Thus, employees, whose companies do not offer such benefits as flexible working-time arrangement, paid time off, or sick leave tend to demonstrate a high level of presenteeism (Bockerman \& Laukkanen, 2010).

When presenteeism occurs, employees often demonstrate lower levels of performance and productivity, feeling more depressed and exhausted (Robertson \& Cooper, 2011). In the long-term, presenteeism may cause serious problems in employees' physical and mental health. The latest estimate is that presenteeism costs United Kingdom business over $£ 15$ b per annum while absenteeism only costs around $£ 9 b$ (Robertson \& Cooper, 2011).

Luo Lu and Hui Yen Lin, Department of Business Administration, National Taiwan University, Taipei City, Taiwan; Cary L. Cooper, Lancaster University Management School, Lancaster University, Lancaster, United Kingdom.

This research was supported by a grant from the Service Science Society of Taiwan (2011-2012) and a grant from the National Science Council, Taiwan (NSC101-2410-H-002-197-MY2).

Correspondence concerning this article should be addressed to Luo Lu, Department of Business Administration, National Taiwan University, No. 1, Sec. 4, Roosevelt Road, Taipei 106, Taiwan, ROC. E-mail: luolu@ ntu.edu.tw
While interest in presenteeism is increasing in the developed Western societies, the majority of the existing work is done in the public health and nursing fields. Scholars have argued that insights from more diverse research perspectives such as human resources management, organizational psychology, and health psychology may benefit the theoretical development in the field (Johns, 2010). This is necessary because most of the existing studies on presenteeism have approached presenteeism as merely an overt behavior (Aronsson, Gustafson, \& Dallner, 2000; Johns, 2010; Johns, 2011), overlooking the underlying psychological process of such an act: why people decide to work while sick? Thus, one aim of the current study is to unravel the underlying motives of the act to better understand presenteeism as a personal experience.

Presenteeism has not often been studied with a view to relate it to personality, and there are not many studies relating it to both antecedents and consequences. In addition, longitudinal studies are rather rare in this field. Though the significance of presenteeism as a fact of modern day work life has been established with large scale surveys in the developed economies such as the Scandinavia countries (e.g., Aronsson, Gustafsson, \& Dallner, 2000; Demerouti, Blanc, Bakker, Schaufeli, \& Hox, 2009), research in nonWestern countries is nonexistent. A recent survey with a national representative sample in Taiwan revealed a striking work week of 48.96 hours ( $\mathrm{Lu}, 2011$ ), while the official figure puts it at a staggering monthly 185.60 hours and on a rising trend (Council of Labor Affairs, Executive Yuan, Taiwan, 2010). Because there have been no surveys on presenteeism in Taiwan, what proportion of this long working hour is contributed by the act of presenteeism is unknown. It is reasonable to speculate that under the cultural imperative of hardworking and perseverance (Lu, Kao, Siu, \& Lu, 2011), Chinese employees may be more likely to report to work even when ill, compared with their Western counterparts. Furthermore, because loyalty and reciprocity ("bao") are highly valued 
virtues in the Chinese culture (Lu, Siu, \& Lu, 2010), employees may push themselves to work when ill to present a good image and avoid social sanctions. In Taiwan, more than $97 \%$ of enterprises are small- and medium-size enterprises (SMEs), and more than $77 \%$ of workers in the total labor force are employed in SMEs (Ministry of Economic Affairs, R.O.C., 2012). The Labor Standards Law in Taiwan grants a worker 7 days of annual paid leave after his or her continuous service in a company for more than 1 year. However, no paid sick leaves are enforced by any labor laws. In effect, with increasing global competition and the constant concern for cost down, only very few large companies have provided benefits including paid leaves and flexible working-time arrangements (Chang, Lu, \& Kuo, 2012); most employees in SMEs are discouraged to take the legitimate annual leaves. The cultural imperative for hardworking and the prevailing pressure for working long hours, compounded with the lack of labor welfare protection, may exacerbate the problem of presenteeism in Taiwan (cf., Bockerman \& Laukkanen, 2010), making it a worthy subject for research and subsequent intervention. Thus, another purpose of the current study is to systematically examine possible consequences of the act of presenteeism on Chinese employees' health and work outcomes to highlight the gravity of the presenteeism problem.

\section{Presenteeism: The Concept and Definition}

Presenteeism is a relatively new concept for the organizational scholars, although it has become an increasingly prevalent phenomenon in today's work world. A definitional consensus is still illusive. As critiqued by Johns (2012), while various definitions of presenteeism all refer to physical presence at work, many have conflated the cause and the effect. For instance, Cooper's (1996) original conception of presenteeism clearly conflates the act of presenteeism (going to work when ill) with its consequences (no longer effective, or any resulting productivity loss). The majority of the medical field approaches presenteeism as "lost productive time"; it does not take a behavioral view of presenteeism that separates out the behavior from the consequences (e.g., Collins et al., 2005; Turpin et al., 2004). While the medical field has consistently defined a construct as lost productive time from being unwell, the impact of ill-health on productivity loss may have been exaggerated. Johns (2011) demonstrated that having controlled for health status and psychosocial (e.g., neuroticism) and organizational factors (e.g., ease of replacement) could account for substantial variances in participants' responses to self-reported presenteeism-related productivity loss. Namely, the commonly proclaimed estimates of productivity loss because of working when ill in literature seem too lofty (e.g., Robertson \& Cooper, 2011), because nonmedical sources of variance appear to contaminate these estimates. This fact also highlights the necessity to expand the narrow focus on health status to include psychosocial and organizational factors as possible antecedents of the act of presenteeism. Furthermore, the construct of presenteeism in a behavioral approach needs further theoretical development. Cooper's definition spells out "what" without explaining "why." Most existing studies also overlooked the motivational dynamism that drives presenteeism as a behavioral manifestation. People may report to work when feeling unwell for very different reasons; therefore, it is worth exploring different motives for the act of presenteeism as the unfolding of a psychological process.

\section{Divergent Motives for Presenteeism}

While certain correlates of presenteeism, such as firm-level work contexts, personal circumstances, and personality traits, have been investigated by a few recent studies (Johns, 2011; Löve, Grimby-Ekman, Eklöf, Hagberg, \& Dellve, 2010), the motives for committing the act of presenteeism remain unexplored. Most of the existing studies have focused on the associations between personality traits, organizational factors, and the behavioral manifestation of presenteeism. For example, Aronsson and Gustafsson (2005) found that difficulties in staff replacement, time pressure, insufficient work resources, and poor personal financial situation had impacts on sickness presenteeism. Furthermore, research has already shown that how employees perceive the working environment matters to the decision of attending work when ill or not (Biron, Brun, Ivers, \& Cooper, 2006). Johns (2011) also found in a sample of Canadian business school graduates that presenteeism days was positively associated with task significance and ease of replacement, and negatively associated with neuroticism, equity, job security, internal health locus of control, and the perceived legitimacy of absence. It is thus plausible to infer that both personality traits (e.g., neuroticism) and work environment factors (e.g., pressure to attend) may contribute to the prevalence of presenteeism. However, the "why" still needs to be systematically explored. As the transactional theory (Lazarus \& Folkman, 1984) posits, people are constantly appraising, interpreting, and making sense of the situation, as well as evaluating their own personal resources to decide the best course of action in every encounter. Thus, from a behavioral perspective, understanding people's motives for committing the act of presenteeism is crucial for a more comprehensive representation of the underlying psychological process.

According to the transactional theory of stress (Lazarus \& Folkman, 1984), people may approach a stressful encounter in different ways: to confront the stressor to master the situation (the "fight" response), or to avoid the stressor to alleviate its noxious impacts (the "flight" response). Some employees might choose to attend work while sick because they believe that they should overcome the discomfort to be loyal to their jobs, coworkers, and customers; while others might force themselves to work because of the fear of financial loss or the backlash of social disapproval. It is thus imperative to look beneath the overt act of presenteeism for its covert driving forces, which we termed approach and avoidance motives. Approach motives refer to the desire to confront the discomfort to abide by one's work values and beliefs of achievement and loyalty to the profession and interested parties. For example, beliefs of self-resiliency and work values of diligence and loyalty may motivate people to come to work despite illness. Avoidance motives refer to the fear of damaging consequences of seeking sick leaves, thus forcing oneself to report to work. For example, fear of salary deduction or performance loss, and the pressure to conform to work practices and expectations from peers or supervisors, may push employees to commit the act of presenteeism.

Our dual conception of the presenteeism motives was tentatively supported by empirical evidence from a recent British study. 
Baker-McClearn, Greasley, Dale, and Griffith (2010) conducted interviews in nine organizations and identified two triggering factors of the presenteeism act, which they termed "personal motivations" and "workplace pressures." Personal motivations include work values and beliefs such as "no one else can do the job," "loyalty to own professional image," and "obligation and commitment to colleagues, clients, and organizations." Workplace pressures refer to the organization's attendance policy, management style, and workplace culture. The so-called personal motivations largely correspond with our approach motivation, while the workplace pressures may be the sources of avoidance motivation. However, we still need to verify this motivational dichotomy in a Chinese work context and to develop a usable measure for quantitative research.

As Lazarus and Folkman (1984) pointed out in the transactional theory of stress, people's personal characteristics would influence both their appraisal of and their habitual way of coping with the stressful situations. Research in stress and coping has accumulated abundant evidence showing that self-efficacy and neuroticism because personality traits are associated with a fight or a flight approach to stressful encounters, respectively (Bandura, 1992; Eysenck, 1990). We thus focused on these two individual difference factors as possible predictors of the approach and avoidance motives.

Bandura (1997) defined self-efficacy as the extent to which people believe they can perform a behavior to gain particular desired outcomes. People with high self-efficacy tend to set challenging goals and act firmly with confidence. In other words, self-efficacy, which refers to stable and global beliefs about one's competence, relates to one's ability to tackle stressors. Theoretically and empirically, self-efficacy has been widely recognized as one of the protective factors in the stress-strain relation (Jex, Bliese, Buzzell, \& Primeau, 2001; Salanova, Peiro, \& Schaufeli, 2002; Schaubroeck, Lam, \& Xie, 2000; Schaubroeck \& Merritt, 1997). Self-efficacy leads people to adopt active coping strategies to deal with the external demands. In the presenteeism context, employees with higher self-efficacy are more likely to possess a stronger approach motive, because they value self-resiliency and self-accomplishment. In other words, self-efficacy drives people to overcome obstacles with a strong belief that they should and are able to confront challenges to maintain performance standards. Though self-efficacy has not been examined in the context of presenteeism, some related personality traits have been. For instance, Löve et al. (2010) found that self-esteem was a predictor of presenteeism in a large sample of Swedish young adults. Johns (2011) has also found that internal health locus of control was positively associated with presenteeism days for Canadian workers. The approach motives may account for the associations between the positive personality traits and the act of presenteeism as observed in the above studies. We thus hypothesized that:

Hypothesis 1a: Self-efficacy would be positively related to the approach motives for committing the act of presenteeism.

In notable contrast to the approach motives, avoidance motives may be solicited by certain pressures and managerial practices that make employees feel obligated to attend work. Baker-McClearn et al.'s (2010) qualitative research revealed several aspects of such workplace pressures. For example, when managers set as role models and attend work when sick makes employees feel obligated to follow suit. Their research also found that work attendance was more important to those whom were sensitive to judgments from clients, colleagues, or supervisors. Some people are more sensitive to social pressures, including attendance-related workplace culture. Neuroticism has long been recognized as a vulnerability factor for stress (Costa \& McCrae, 1992; Eysenck, 1990). Neuroticism refers to relatively stable tendencies to respond with negative emotions to threat, frustration, or stress (Lahey, 2009). Neurotic people are more susceptible to interpersonal influence with a fear of being disliked by others and exhibit a tendency to evaluate environments with pessimistic perspectives (Eysenck, 1990). Thus, neuroticism might predispose employees to worry about negative consequences, such as financial loss, job insecurity, difficulty of replacement, and social disapproval for taking sick leave (Baker-McClearn et al., 2010). Employees with high neurotic tendency might also worry about projected personal image; for example, being a lousy worker. Thus, rather than taking a leave of absence, they might force themselves to attend work with an underlying avoidance motive to avoid criticism and penalty. We thus hypothesized that:

Hypothesis 1 : Neuroticism would be positively related to the avoidance motives for committing the act of presenteeism.

Although the underlying psychological motives may be different, the behavioral manifestation of presenteeism is the same. That is to say, presenteeism as an overt behavior is observed regardless of approach or avoidance motives driving the act. We thus hypothesized that:

Hypothesis 2: Both approach and avoidance motives of committing the act of presenteeism would be positively related to the behavioral frequency of presenteeism.

\section{Consequences of Presenteeism}

The majority of existing research in presenteeism has been conducted in public health and epidemiology fields, with a focus on the association between presenteeism and health damages. Cross-sectional studies have demonstrated that presenteeism is negatively related to employees' health among health workers (Aronsson et al., 2000; Caverley, Cunningham, \& MacGregor, 2007; Claus \& Johan, 2008; Elstad \& Vabo, 2008).

The detrimental effects of presenteeism on health can be explained with the recovery theory (Meijman \& Mulder, 1998). People need resources to gain a complete recovery from attending work while ill, including time to rest and detachment from their jobs. The continuous presenteeism might trigger a downward spiral of worsening health conditions and even stronger pressure to commit presenteeism in the long term. Namely, if employees go to work in spite of physical or psychological morbidity or discomfort, depriving themselves of recovery opportunities, they might suffer more from the accumulating tiredness and fatigue. Johns (2011) found that presenteeism was negatively associated with overall health. Bergström, Bodin, Hagberg, Aronsson, and Josephson (2009) have also found that presenteeism was a significant risk factor for future sick leave of more than 30 days, indicative of serious health problems, in two large samples. We thus hypothesize that: 
Hypothesis 3a: The act of presenteeism would be negatively related to employees' mental and physical health.

Burnout is a multifaceted emotional syndrome of exhaustion, representing chronic reactions and negative affective response to prolonged stress at work (Maslach, Schaufeli, \& Leiter, 2001; Shirom, 2003). In a rare longitudinal three-wave study, Demerouti et al. (2009) found that exhaustion had a reciprocal relation with presenteeism in a sample of Dutch nurses. They suggested that when employees experience exhaustion, they mobilize compensation strategies, which ultimately increases their exhaustion. To further examine the detrimental effect of presenteeism on exhaustion across a wider variety of occupations, we hypothesized that:

Hypotheis $3 b$ : The act of presenteeism would be positively related to employees' exhaustion.

Presenteeism might not only be hazardous to employees' health but also affect their work outcomes. Being at work while having discomfort or illness might solicit negative affective responses, which triggers discontentment. Specifically, feeling pressured to work when sick may dampen job satisfaction. Indeed, presenteeism is more common among medical staff with lower job satisfaction resulting from both the nature of their job and high attendance requirement (Aronsson et al., 2000). The recovery theory (Meijman \& Mulder, 1998) could again account for the detrimental effect of presenteeism on job satisfaction. No matter whether employees perform presenteeism because of their overcommitment to work (Hansen \& Andersen, 2008), or because of fear of damaging consequences, lack of sufficient opportunity to recover will eventually damage job satisfaction. The qualitative study (Baker-McClearn et al., 2010) also noted that employees who had experienced frequent presenteeism had a tendency to describe their jobs as being stressful and unsatisfying. We thus hypothesized that:

Hypothesis 3c: The act of presenteeism would be negatively related to employees' job satisfaction.
What we know about presenteeism is largely based upon empirical studies conducted by scholars in medical and nursing fields, with an occupational health and epidemiological perspective; thus, job performance is not of their focal concern. However, presenteeism might have a critical impact on productivity (Robertson \& Cooper, 2011) via employees' performance. Economists have attempted to estimate productivity loss with large-scale surveys of employees by quantifying presenteeism into work hours and monetary equivalent (Burton, Conti, Chen, Schultz, \& Edington, 1999; Levin-Epstein, 2005), namely using the econometric approaches. We attempted to use the two-wave longitudinal design to estimate the strength of the association between the act of presenteeism and subjective job performance, including task and contextual performance. We thus hypothesized that:

Hypothesis $3 d$ : The act of presenteeism would be negatively related to employees' job performance.

To sum, we focused on "sickness presenteeism"; namely, employees are physically present but they actually feel they should take sick leave (Aronsson et al., 2000). We reasoned that approach and avoidance might be two distinct motives for committing the act of presenteeism, and each was linked to different personality factors. We also examined individual health and work consequences of presenteeism. The thrust of the present study is that we embedded the systematic study of the act of presenteeism and its consequences for the individual in a Chinese cultural context. Such an effort would generate valuable evidence supporting the universality of the phenomenon and generalizability of established Western findings to a society of vastly different social, cultural, and economic features. Our research framework is shown in Figure 1.

\section{Method}

\section{Participants and Procedures}

The participants in our study were full-time employees working in different organizations of diverse industries across Taiwan. We

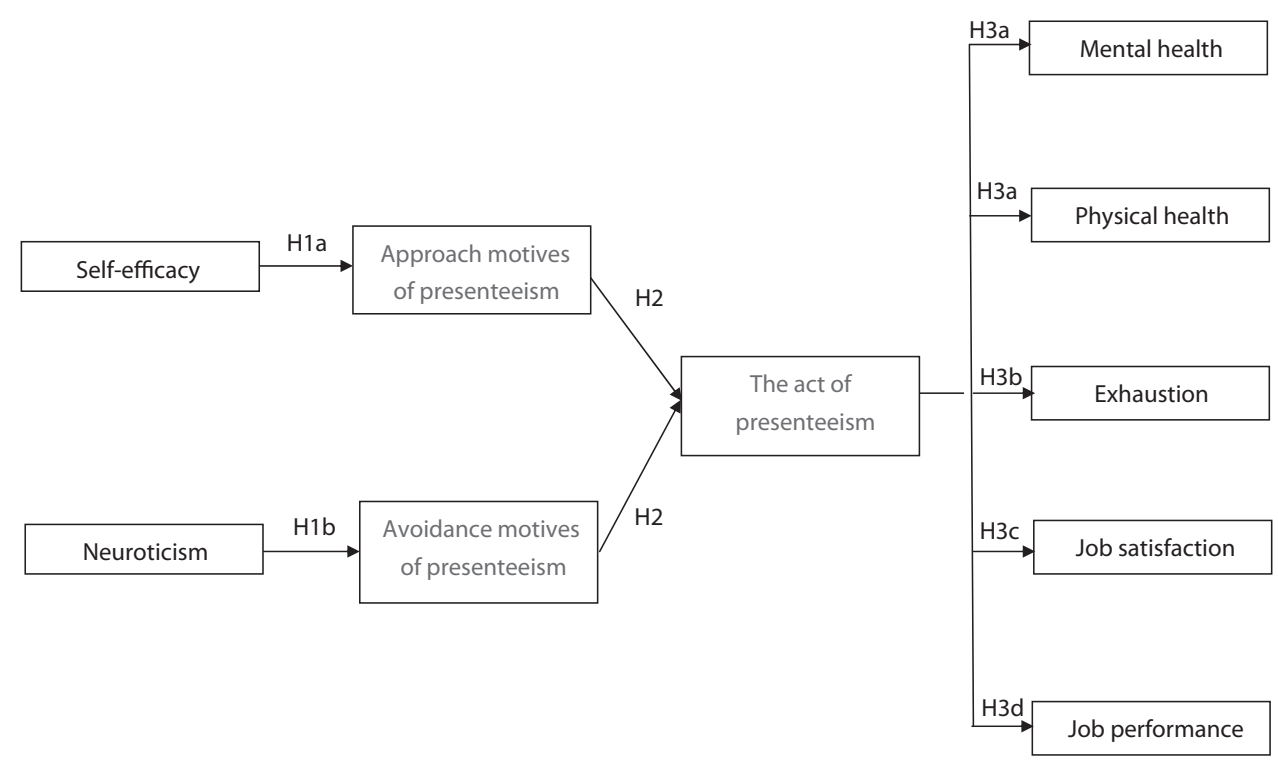

Figure 1. The research framework. 
employed a longitudinal panel design in which personality traits and motives were measured in the first questionnaire only, whereas motives, the act of presenteeism, and consequences of presenteeism were measured in both questionnaires completed by the panel with 2 months in between. We recruited participants from working adults attending evening classes in a large university to maximize both the heterogeneity of the sample and a high response rate of the two-wave panel design.

At Time 1 (T1), along with the first questionnaire, each participant received a cover letter informing them the purpose of the study, the commitment required, and assuring them of anonymity. Participants completed structured questionnaires at class. All participants had full-time jobs. A total of 319 questionnaires were distributed and 309 returned (T1 response rate of $96 \%$ ). At Time 2 (T2), 309 questionnaires were distributed and 245 participants had data for both times (retention rate of $79 \%$ ). As a precaution, we systematically examined differences between employees in the panel sample and the dropouts with regard to demographic characteristics as well as the mean scores on the study variables. Analyses revealed no significant differences whatsoever. We thus concluded that no serious selection problems because of panel loss had occurred.

The sample was $53.1 \%$ men and $46.9 \%$ women, with a mean age of $37.91(S D=7.51)$ and mean job tenure of 7.02 years $(S D=$ 6.96). Over half of the sample $(55.6 \%)$ was married. Over half of the respondents $(61.3 \%)$ were managers at various levels. The majority of participants worked in the service industry (44.1\%) and manufacturing industry (34.6\%). The rest of the sample worked in education, government organizations, and medical/health industry.

\section{Instruments}

The questionnaire survey was administered in Chinese, and measures for assessing personality and outcomes of presenteeism have established Chinese versions used in previous studies with satisfactory reliability and validity. These references will be given along with the original English version when every scale is introduced below.

Self-efficacy. We used the General Self-Efficacy Scale (5 items; Schwarzer, Babler, Kwiatek, Schroder, \& Zhang, 1997; Lu, Chang, \& Lai, 2011, for the Chinese version; e.g., "I am confident that I could deal efficiently with unexpected events") to measure self-efficacy. Each item was rated on a 6-point scale $(1=$ not at all true, $6=$ very true), with high scores representing high levels of self-efficacy. The internal consistency $\alpha$ was .84 in the present sample.

Neuroticism. We used the Neuroticism subscale of Big-Five Mini-Marker Set (8 items; Saucier, 1994; Wu, Lu, Ku, \& Chang, 2010, for the Chinese version; e.g., "Moody"; "Relaxed," [reversed score]). Each item was rated on a 5-point scale ( $1=$ not at all, 5 = very much so), with high scores representing high levels of neuroticism. The internal consistency $\alpha$ was .80 in the present sample.

Motives for presenteeism. We have argued that there may be diverse motives beneath the same behavioral manifestation of presenteeism. Because the motivational dichotomy is a new concept, we thus conducted a series of preliminary studies to develop a suitable scale to measure approach and avoidance motives. A combined inductive and deductive approach to item generation as suggested by Hinkin (1995) was adopted. At Step 1, we conducted qualitative interviews with 7 informants working in a variety of industries and with different job positions, including managers in high technology industries, staff in financial banks, head nurses, salesmen, and engineers. The reasons that informants gave for going to work when ill largely corroborated those found in BakerMcClearn et al.'s study (2010). Nonetheless, our informants were more concerned about the effects of taking sick leaves on work relationships, especially those with their supervisors. At Step 2, we conducted an online survey $(N=209)$ using an open-ended question "Why did you go to work while ill?" Information generated from these two preliminary studies could be readily categorized as either approach or avoidance motives. The former refers to employees attending work while sick because they want to overcome the discomfort to be loyal to their jobs, coworkers, and customers. The latter refers to employees deciding to come to work while sick because of worries about being punished, blamed, or leaving a bad impression on important others. At Step 3, we compiled 6 items describing the avoidance motives and 7 items describing the approach motives. We tested these 13 items on a large sample of participants $(N=769)$. Following exploratory factor analysis (EFA), one item in the avoidance motives subscale was deleted because of cross-loading, and three items in the approach motives subscale were deleted to focus on the main idea of "perseverance and loyalty." The two-factor structure was confirmed, accounting for $61.78 \%$ of the total variance. Finally, at Step 4, another independent sample of 307 participants completed the revised 9-item measure. A principal components analysis was again computed with varimax rotation. This round of EFA too yielded two factors accounting for $68.10 \%$ of the total variance with a zero correlation between the two factors. Thus, 5 items of avoidance motives and 4 items of approach motives were finalized (all items are listed in the lower portion of Table 1) and used in the hypotheses testing study reported in this article. Each item was rated on a 4 -point scale $(1=$ not at all, $4=$ very much so), with high scores representing high levels of avoidance and approach motives. The internal reliability coefficients of the avoidance and approach motives were .77 and .80 at $\mathrm{T} 1$, and .70 and .86 at $\mathrm{T} 2$ in the present sample. Test-retest reliability coefficients were .34 $(p<.001)$ and $.32(p<.001)$, respectively.

The act of presenteeism. We developed 2 items to access the behavioral frequency of presenteeism (listing in the upper portion of Table 1), similar to the construct of "sickness presenteeism" (Aronsson et al., 2000; Demerouti et al., 2009). Results of EFA showed that the 2 items represented a single construct $(N=307$ as used in finalizing the motives scale), accounting for $88.30 \%$ of the total variance. The focal question on presenteeism was "Have you experienced the following in the last 6 months?" Each item was rated on a 4 -point scale $(1=$ never, $4=$ more than 5 times $)$, with high scores representing more frequent act of presenteeism. The internal consistency $\alpha$ was .88 (T1) and .86 (T2) in the present sample, and test-retest reliability was $.31(p<.001)$.

Mental and physical health. Two subscales from Occupational Stress Indicator (OSI-2; Cooper, Sloan, \& Williams, 1998; Lu, Tseng, \& Cooper, 1999, for the Chinese version) were used to measure employees' subjective health symptoms: (a) Mental Health Scale (12 items; e.g., "Would you say that you tended to be a rather overconscientious person who worries about mistakes or actions that you may have taken in the past, such as decisions?") 
Table 1

Items Assessing the Motives and Behavioral Frequency of Presenteeism

\begin{tabular}{ll}
\hline & \multicolumn{1}{c}{ Items } \\
\hline $\begin{array}{c}\text { Behavioral frequency } \\
\text { of presenteeism }\end{array}$ & $\begin{array}{l}\text { Have you experience the following in the last } 6 \\
\text { months? } \\
\text { 1. Although you feel sick, you still force yourself } \\
\text { to go to work. }\end{array}$ \\
2. Although you have physical symptoms such as \\
headache or backache, you still force yourself \\
to go to work. \\
When the above happened, you forced yourself \\
to go to work because ... \\
1. I worried that I might lose job. \\
$\begin{array}{l}\text { 2. I worried that I might suffer economic loss. } \\
\text { 3. I worried that my supervisor might think badly } \\
\text { of me. }\end{array}$ \\
$\begin{array}{l}\text { 4. I worried that my colleagues might think badly } \\
\text { of me. }\end{array}$ \\
$\begin{array}{l}\text { 5. I worried that I might burden my colleagues. } \\
\text { 1. I believed that I should persevere to go to } \\
\text { work. }\end{array}$ \\
$\begin{array}{l}\text { 2. I believed that I should be loyal to the } \\
\text { customers. }\end{array}$ \\
$\begin{array}{l}\text { 3. I believed that I should keep up with team } \\
\text { schedule. } \\
\text { 4. I believed that I should be loyal to my } \\
\text { profession. }\end{array}$
\end{tabular}

and (b) Physical Health Scale (6 items; e.g., "Pricking sensations or twinges in parts of your body"). Each item was rated on a 6-point scale, with higher scores indicating better health ( $1=$ very frequent, $6=$ never $)$. The internal reliability coefficients of mental and physical health scales were .83 and .82 at T1, and .86 and .90 at T2 in the present study, and test-retest reliability was .33 ( $p<$ $.001)$ and $.29(p<.001)$.

Exhaustion. Exhaustion was measured with 9 items (Maslach \& Jackson, 1986; Lu, Lee, \& Shieh, 2005, for the Chinese version; e.g., "I feel emotionally drained from my work"). Each item was rated on a 7 -point scale $(0=$ never, $6=$ every day $)$, with high scores representing high levels of exhaustion. The internal consistency $\alpha$ was .93 (T1) and .92 (T2) in the present sample, and test-retest reliability was $.40(p<.001)$.

Work outcomes. Two scales were used to measure employees' work outcomes: (a) the Job Satisfaction Scale (3 items; Cammann, Fichman, Jenkins, \& Klesh, 1979; Lu et al., 2009, for the Chinese version; e.g., "All in all, I am satisfied with my job"). Each item was rated on a 6 -point scale $(1=$ never, $6=$ very often $)$, with higher scores indicating higher job satisfaction. The internal consistency $\alpha$ was .86 (T1) and .88 (T2) in the present sample, and test-retest reliability was $.39(p<.001)$. (b) the Job Performance Scale (23 items; Motowidlo \& Van Scotter, 1994; Chih, Lee, \& Chen, 2008, for the Chinese version), which included task performance and contextual performance. Each item was rated on a 5 -point scale $(1=$ much below average, $6=$ very above average $)$, with higher scores indicating higher job performance. The internal consistency $\alpha$ was .90 (T1) and .92 (T2) in the present sample, and test-retest reliability was $.39(p<.001)$.

In addition, information on gender $(\operatorname{coded}$ female $=0$, male $=$ 1 ), marital status (coded married $=1$, not married $=0$ ), tenure on the job, and position (coded managers $=1$, employees $=0$ ) were recorded. These were intended as control variables. Previous research has found that some organizational and work factors were associated with presenteeism (Bockerman \& Laukkanen, 2010). We thus included two contextual factors as control variables: organizational pressure for attendance and work replacement. The former was measured by 2 items asking participants about their perception of managerial policy on and pressure for attendance. The latter was measured by 3 items pertaining to job replacement arrangements in the organization.

\section{Convergent and Divergent Validity of Constructs}

We conducted confirmatory factor analysis (CFA) to test for convergent and divergent validity of each construct in this study: self-efficacy, neuroticism, approach motives, avoidance motives, presenteeism, mental health, physical health, exhaustion, job satisfaction, and job performance. According to Hair, Black, Babin, Anderson, and Tatham (1998), convergent validity may be established when (a) all individual items loaded significantly on their constructs, (b) composite reliability (CR) is greater than .70, and (c) the average variances extracted (AVE) is greater than .50. Our CFA results revealed that all scale items loaded significantly ( $p<$ .001) on their designated construct, indicating acceptable individual item reliability. $\mathrm{CR}$ is an indicator of the internal consistency of a construct. In the present study, CR for the 10 constructs ranged from .86 to .94 , indicating acceptable internal consistency of all constructs. Finally, AVE represents the percentage of variances in a latent construct can be explained by its indicators (observed variables). In the present study, AVE for most constructs ranged from .62 to .78, except for neuroticism (.43), mental health (.40), and job performance (.39). Overall, constructs in our study had acceptable convergent validity.

Discriminant validity may be established when relations between different constructs are weaker than those within each construct (Hair et al., 1998). In other words, when examining a correlation matrix, the square root of AVE should be greater than all correlation coefficients involving the construct. In our study, the square root of AVE was .62, .43, .53, .52, .70, .40, .54, .65, .78, and .39 for self-efficacy, neuroticism, approach motives, avoidance motives, presenteeism, mental health, physical health, exhaustion, job satisfaction, and job performance; all are greater than correlation coefficients involving each of the construct (see Table 2) However, the square root of AVE for physical health is smaller than the correlation between physical health and exhaustion. Overall, the discriminant validity was acceptable for all the constructs in the present study.

\section{Results}

Prior to the hypotheses testing, bivariable correlations were computed and results shown in Table 2. Consistent with our expectation, presenteeism was moderately correlated with mental health, physical health, and exhaustion in the expected direction at both times. Self-efficacy was significantly correlated with approach motives, whereas neuroticism was significantly correlated with avoidance motives.

The study hypotheses were tested with a series of hierarchical regression analyses. Hypothesis 1 stated that self-efficacy and neuroticism would be positively related to approach and avoidance 
motives, respectively. We entered both personality traits at the same step after controlling for sex, marriage, seniority and position. Organizational pressure for attendance and work replacement were also controlled. The results are reported in Table 3, showing that self-efficacy significantly predicted approach motives, whereas neuroticism did not. In contrast, neuroticism significantly predicted avoidance motives, whereas self-efficacy did not. Therefore, Hypotheses 1a and $1 \mathrm{~b}$ were supported.

To test Hypothesis 2, presenteeism was regressed on approach and avoidance motives after controlling for gender, marriage, seniority, position, and contextual factors of attendance pressure and work replacement. Results are presented in Table 4. Both approach and avoidance motives significantly predicted presenteeism. Hypothesis 2 was supported.

To Test Hypotheses 3a-3d, rather than putting a bunch of variables in the equation, we controlled for all time invariant covariates by doing the regression with difference scores (Allison, 2005). Regression with difference scores can control fixed effects and is used to analyze longitudinal data with repeated measures on both independent and dependent variables. They have the attractive feature of controlling for all stable characteristics of the individuals, whether measured or not. This is accomplished by using only within-individual variation to estimate the regression coefficients (Allison, 2005). We first entered all the individual control variables in the regression models. At the second step, we entered contextual control variables. At the third step, we entered the difference score of presenteeism (presenteeism at T2 minus presenteeism at $\mathrm{T} 1$ ), to control for fixed effects. The results are reported in Table 5, showing that having controlled for individual and contextual factors, as well as fixed effects, difference score of presenteeism significantly predicted difference scores of mental health, physical healthy, exhaustion, and job satisfaction. Thus, Hypotheses $3 \mathrm{a}-3 \mathrm{c}$ were supported. Hypothesis $3 \mathrm{~d}$, however, was not supported.

Although we did not propose a priori hypothesis, it is nonetheless interesting to examine the possible reciprocal associations between presenteeism and the outcomes (i.e., physical health, mental health, exhaustion, job satisfaction, job performance). We conducted a cross-lagged structural equation modeling (SEM) analyses. Results are shown in Table 6. The Cross-Lagged Model yielded a satisfactory fit to the data. We then tested a competing model (Constrained Model), constraining the paths from presenteeism (T1) to physical health, mental health, exhaustion, job satisfaction, and job performance at $\mathrm{T} 2$ to be equal to paths from physical health, mental health, exhaustion, job satisfaction, and job performance at $\mathrm{T} 1$ to presenteeism (T2). The fit to the data was not significantly improved ( $\chi^{2}$ differences were not statistically significant for the model comparison). Thus, there might be potential reciprocal associations between presenteeism and all forms of outcomes in this study.

\section{Discussion}

One aim of the present research was to shed light on possible motives for committing presenteeism, to remedy for shortcomings in the existing literature which focuses on the behavioral manifestation and environmental correlates of the act. Furthermore, we used a longitudinal two-wave panel design to systematically examine the effects of presenteeism in a wide-range of health and 
Table 3

Hierarchical Regression Analysis Predicting Motives for Presenteeism

\begin{tabular}{|c|c|c|c|c|c|}
\hline \multicolumn{2}{|r|}{ Dependent variable } & \multicolumn{2}{|c|}{ Approach motives } & \multicolumn{2}{|c|}{ Avoidance motives } \\
\hline Step & Predictors & $\beta$ & $\Delta R^{2}$ & $\beta$ & $\Delta R^{2}$ \\
\hline \multirow[t]{4}{*}{1} & Gender & -.12 & & .01 & \\
\hline & Marriage & .06 & & -.08 & \\
\hline & Seniority & $-.15^{*}$ & & $-.16^{*}$ & \\
\hline & Position & $.15^{*}$ & $.11^{* * * *}$ & $-.18^{*}$ & $.07^{* *}$ \\
\hline \multirow[t]{2}{*}{2} & Organizational pressure for attendance & $.19^{* *}$ & & $.24^{* * * *}$ & \\
\hline & Work replacement & .00 & $.04 *$ & -.02 & $.07^{*}$ \\
\hline \multirow[t]{4}{*}{3} & Self-efficacy & $.29^{* * * *}$ & & .04 & \\
\hline & Neuroticism & .02 & $.09^{* * * *}$ & $.18^{*}$ & $.03^{*}$ \\
\hline & Total $R^{2}$ & .17 & & .17 & \\
\hline & Final $F(d f)$ & $5.05^{* * * *}$ & $(8,194)$ & $4.80^{* * * * *}$ & $(8,191)$ \\
\hline
\end{tabular}

work-related outcomes. The first thrust of our study is that we delineated two distinct underlying motives and uncovered that personality factors (self-efficacy and neuroticism) were significantly related to the approach and avoidance motives, respectively. To our knowledge, the present study is the first one to conceptualize and measure the motives for presenteeism and to relate them to personality predispositions. It is useful to map out the different psychological mechanisms which trigger the same overt behavioral manifestations of presenteeism. Conceptualizing the approach/avoidance motives and verifying their phenomenological validity with qualitative interview data, open-ended question responses, and robust EFA results, is a major step forward toward understanding the push and pull forces of committing the act of presenteeism in today's workforces.

The second thrust of the present study is that we systematically examined consequences of presenteeism in both health and work domains. Although there have been a few studies looking at various health and/or work consequences of presenteeism, they mostly adopt a cross-sectional design, thus leaving room for confounding between the act of presenteeism and its supposedly consequences. Indeed, in a

Table 4

Hierarchical Regression Analysis Predicting Presenteeism

\begin{tabular}{|c|c|c|c|}
\hline \multicolumn{2}{|c|}{ Dependent variable } & \multicolumn{2}{|c|}{ Presenteeism } \\
\hline Step & Predictors & $\beta$ & $\Delta R^{2}$ \\
\hline \multirow[t]{4}{*}{1} & Gender & $-.13^{*}$ & \\
\hline & Marriage & .00 & \\
\hline & Seniority & -.14 & \\
\hline & Position & .11 & $.05^{*}$ \\
\hline \multirow[t]{2}{*}{2} & $\begin{array}{l}\text { Organizational pressure } \\
\text { to attendance }\end{array}$ & $.15^{*}$ & \\
\hline & Work replacement & -.11 & $.06^{* * *}$ \\
\hline \multirow[t]{4}{*}{3} & Approach motives & $.20^{\text {*** }}$ & \\
\hline & Avoidance motives & $.17^{* * *}$ & $.07^{* * *}$ \\
\hline & Total $R^{2}$ & .18 & \\
\hline & Final $F(d f)$ & $5.63^{* * * * *}$ & $27^{* * * *}(8,194)$ \\
\hline
\end{tabular}

Note. Gender: $0=$ female, $1=$ male; Marriage: $0=$ single separated $/$ widowed, $1=$ married/cohabiting/remarried ; Position: $0=$ nonmanager, $1=$ manager

${ }^{*} p<.05 .{ }^{* *} p<.01 .{ }^{* * *} p<.001$. rare longitudinal study, Demerouti et al. (2009) did find that the relationship between presenteeism and exhaustion was reciprocal. We adopted a different strategy analyzing the longitudinal data to support our proposed causal inferences pertaining to presenteeism and its consequences. Specifically, using fixed effects modeling we were able to rule out baseline effects of individual's health, work attitude, job performance, and behavioral tendency of committing the act of presenteeism. Consequently, presenteeism demonstrated a "net impact" across the board on all outcomes except job performance, including mental health, physical health, exhaustion, and job satisfaction. These findings were consistent with what have been found in previous studies conducted in Western societies (e.g., Aronsson et al., 2000; Caverley et al., 2007; Claus \& Johan, 2008; Elstad \& Vabo, 2008), but with a stronger methodological thrust. Although reciprocal relations between presenteeism and strains are not the foci of the present study, our SEM results corroborated and further extended Demerouti et al.'s findings to health and work outcomes (Table 6). Thus, the possibility that relationships between presenteeism and physical health, mental health, exhaustion, and job satisfaction may be reciprocal needs further theoretical and empirical exploration.

It is worth noting that we failed to find a lasting negative impact of presenteeism on job performance 2 months later. One possible reason may be that the 2-month interval was not long enough to accumulate the fatigue to damage work performance. Future research should extend the time frame when examining the long-term impact of presenteeism. Another possible reason for there being no significant long-term impact may be the opportunity of recovering from accumulated loss of performance resulting from presenteeism. When Dew, Keefe, and Small (2005) interviewed nurses in focus groups about their experiences of presenteeism, some nurses used a metaphor of "sanctuary" and described their teams as "family." Those nurses were highly engaged in their jobs and with the help of their "family," they worked through mild sickness and eventually felt better or ignored discomfort altogether. It thus seems that when social resources are mobilized, employees may be better equipped to cope with the noxious effects of presenteeism, thus containing its impacts in a relatively short time period without developing into a chronic aversive condition. More important, resources, whether personal or social, that can help employees to cope and adapt in the context of presenteeism deserve more research attention in the future. The last but not the least 
Table 5

Hierarchical Regression Analysis Predicting Outcomes of Presenteeism

\begin{tabular}{|c|c|c|c|c|c|c|c|c|c|c|c|}
\hline \multicolumn{2}{|r|}{$\begin{array}{l}\text { Difference score of } \\
\text { dependent variable }\end{array}$} & \multicolumn{2}{|c|}{ Mental health } & \multicolumn{2}{|c|}{ Physical health } & \multicolumn{2}{|c|}{ Exhaustion } & \multicolumn{2}{|c|}{ Job satisfaction } & \multicolumn{2}{|c|}{ Job performance } \\
\hline Step & Predictors & $\beta$ & $\Delta R^{2}$ & $\beta$ & $\Delta R^{2}$ & $\beta$ & $\Delta R^{2}$ & $\beta$ & $\Delta R^{2}$ & $\beta$ & $\Delta R^{2}$ \\
\hline \multirow[t]{4}{*}{1} & Gender & .10 & & .08 & & .01 & & .12 & & .12 & \\
\hline & Marriage & -.12 & & .00 & & .04 & & -.05 & & .00 & \\
\hline & Seniority & .03 & & .01 & & -.02 & & -.07 & & .10 & \\
\hline & Position & .01 & .02 & -.05 & .01 & .06 & .01 & -.10 & .04 & $-.20^{* * *}$ & $.05^{*}$ \\
\hline \multirow[t]{2}{*}{2} & $\begin{array}{l}\text { Organizational pressure } \\
\text { to attendance }\end{array}$ & .06 & & .06 & & -.02 & & .03 & & .01 & \\
\hline & Work replacement & .03 & .01 & -.05 & .01 & .10 & .01 & -.06 & .01 & .03 & .00 \\
\hline \multirow[t]{3}{*}{3} & $\begin{array}{l}\text { Difference score of } \\
\text { Presenteeism }\end{array}$ & $-.29^{* * * *}$ & $.08^{* * * *}$ & $-.32^{* * * *}$ & $.10^{* * *}$ & $.27^{* * * *}$ & $.07^{* * *}$ & $-.19^{* *}$ & $.03^{* *}$ & -.07 & .01 \\
\hline & Total $R^{2}$ & .11 & & .12 & & .09 & & .08 & & .06 & \\
\hline & Final $F(\mathrm{df})$ & $3.30^{* * * *}$ & $(7,181)$ & $3.67^{* * * *}$ & $(7,197)$ & $2.56^{* * * *}$ & $(7,192)$ & $2.34^{* * * *}$ & $(7,198)$ & 1.59 & $(7,192)$ \\
\hline
\end{tabular}

Note. Gender: $0=$ female, $1=$ male; Marriage: $0=$ single separated/widowed, $1=$ married/cohabiting/remarried Position: $0=$ nonmanager, $1=$ manager. ${ }^{*} p<.05$. *** $p<.01$. **** $p<.001$.

thrust of the present study is the utility of Chinese employees for validating and extending Western-based theories and inferences on presenteeism.

It should be kept in mind that there are several limitations inherent to this study. First, this was an exploratory study. We acknowledge that theories generated and measurements developed in one study should be tested and refined with more empirical evidence. Hence, future research needs to examine the generalizability of the approach/ avoidance motives constructs and validate/revise our newly developed presenteeism measures (motives and behavior). Second, our survey was conducted using self-report method. Self-assessed scales mainly tap individual subjective experiences, which reflect the reality an individual observes rather than the reality it actually exists (Podsakoff, MacKenzie, Lee, \& Podsakoff, 2003). Job performance measured by self-report measures might be biased, though our two-wave panel design might mitigate some potential biases. Future research should adopt multiple measures of the constructs from multiple sources using multiple methods. Third, to the best of our knowledge, this is the first study on presenteeism involving Chinese workers. However, the convenient samples we recruited in Taiwan may limit the generalization of our findings. Although our use of part-time business school adult students ensured some heterogeneity of the sample, the relatively small sample size may constrain the statistical power for hypothesis testing. Future studies should strive for larger and more representative samples to establish the generalizability of findings in the present study and those from Western studies. In addition, lack of firm-level controls may add to the omitted variable bias, though we controlled for some of the organizational factors, such as organizational pressure for attendance and work replacement. Last but not the least, we were not able to collect time series data to incorporate the impacts of the macroeconomic conditions. Longer term longitudinal research is needed to clarify impacts of both macrolevel economic and microlevel individual factors on presenteeism.

In the current study, we delineated two diverse motives for presenteeism and systematically explored the health and work consequences of presenteeism. Although there has been discussion and empirical work on presenteeism in the developed West, our perspective is unique and distinct as we focused on the psychological process of motives leading to the act of presenteeism. Our findings of the diverse motives for presenteeism provide a unique contribution to the literature. More important, as we have demonstrated in this study, presenteeism would not only depress employees' job satisfaction but also damage their health. Thus, we urge organizations and managers to pay more attention to employees' act of presenteeism to help them cope with work stress and personal discomfort more effectively. To do so, personality traits and underlying motives need to be taken into account. These will be promising agendas both for future research and intervention practices. Informed by our findings, personal beliefs of selfefficacy predispose employees to an approach orientation when fallen ill: they may push themselves to work to show perseverance and loyalty to the profession and involved parties. For such diligent employees, managers may need to affirm their work ethics but at the same time resocialize them the value of rest and recovery. In contrast, as we also found that neuroticism as a personality trait predisposes employees to an avoidance orientation when fallen ill:

Table 6

Summary of the Structural Equation Modeling Analysis of Reciprocal Relations Between Presenteeism and Outcomes

\begin{tabular}{lccccc}
\hline \multicolumn{1}{c}{ Model } & $\chi^{2}$ & $d f$ & $p$ & $\begin{array}{c}\text { Comparative } \\
\text { fit index }\end{array}$ & $\begin{array}{c}\text { Root mean square } \\
\text { error of approximation }\end{array}$ \\
\hline Cross-lagged & 287.93 & 148 & .000 & .95 & .07 \\
Constrained & 291.44 & 151 & .000 & .95 & .07 \\
Model comparison & $\Delta \chi^{2}=3.51$ & 3 & $n s$ & & \\
\hline
\end{tabular}

Note. $n s=$ not significant. 
they may push themselves to work to avoid feared social backlashes. For such anxious employees, managers may need to reassure them the legitimacy of sick leaves and take concrete steps to prevent any repercussions.

Our concluding message is that, employees' motives for committing an overt behavior at work, and individual differences in such a psychological process should be unpacked, examined, and incorporated in our quest for promoting better work adjustment and more effective managerial practices.

\section{References}

Allison, P. D. (2005). Fixed effects regression methods for longitudinal data using SAS. Cary, NC: SAS Institute Inc.

Aronsson, G., \& Gustafsson, K. (2005). Sickness presenteeism: Prevalence, attendance-pressure factors, and an outline of a model for research. Journal of Occupational and Environmental Medicine, 47, $958-$ 966. doi:10.1097/01.jom.0000177219.75677.17

Aronsson, G., Gustafsson, K., \& Dallner, M. (2000). Sick but yet at work: An empirical study of sickness presenteeism. Journal of Epidemiology and Community Health, 54, 202-509. doi:10.1136/jech.54.7.502

Baker-McClearn, D., Greasley, K., Dale, J., \& Griffith, F. (2010). Absence management and presenteeism: The pressures on employees to attend work and the impact of attendance on performance. Human Resource Management Journal, 20, 311-328. doi:10.1111/j.1748-8583.2009 .0018.x

Bandura, A. (1997). Self-efficacy: The exercise of control. New York, NY: Freeman.

Bergström, G., Bodin, L., Hagberg, J., Aronsson, G., \& Josephson, M. (2009). Sickness presenteeism today, sickness absenteeism tomorrow? A prospective study on sickness presenteeism and future sickness absenteeism. Journal of Occupational and Environmental Medicine, 51, 629638. doi:10.1097/JOM.0b013e3181a8281b

Biron, C., Brun, J. P., Ivers, H., \& Cooper, C. L. (2006). At work but ill: Psychosocial work environment and well-being determinants of presenteeism propensity. Journal of Public Mental Health, 5, 26-37. doi: $10.1108 / 17465729200600029$

Bockerman, P., \& Laukkanen, E. (2010). What makes you work while you are sick? Evidence from a survey of workers. The European Journal of Public Health, 20, 43-46. doi:10.1093/eurpub/ckp076

Burton, W. N., Conti, D. J., Chen, C. Y., Schultz, A. B., \& Edington, D. W. (1999). The role of health risk factors and disease on worker productivity. Journal of Occupational and Environmental Medicine, 41, 863-877. doi:10.1097/00043764-199910000-00007

Cammann, C., Fichman, M., Jenkins, D., \& Klesh, J. (1979). The Michigan organizational assessment questionnaire. Unpublished manuscript, University of Michigan.

Caverley, N., Cunningham, J. B., \& MacGregor, J. N. (2007). Sickness presenteeism, sickness absenteeism, and health following restructuring in a public service organization. Journal of Management Studies, 44, 304. doi:10.1111/j.1467-6486.2007.00690.x

Chang, T. T., Lu, L., \& Kuo, C. Y. (2012). Effects of work resources on work-to-family conflict and work outcomes. Organization and Management, 5, 101-135.

Chih, J. T., Lee, H. W., \& Chen, F. Y. (2008). The Relationship between Big Five Model and job performance. Operation Management Reviews, 4, 1-9.

Claus, D. H., \& Johan, H. A. (2008). Going ill to work: What personal circumstances, attitudes and work-related factors are associated with sickness presenteeism? Social Science \& Medicine, 67, 956-964. doi: 10.1016/j.socscimed.2008.05.022

Collins, J. J., Baase, C. M., Sharda, C. E., Ozminkowski, R. J., Nicholson, S., Billotti, G. M., \& Berger, M. L. (2005). The assessment of chronic health conditions on work performance, absence, and total economic impact for employers. Journal of Occupational and Environmental Medicine, 47, 547-557. doi:10.1097/01.jom.0000166864.58664.29

Cooper, C. (1996). Hot under the collar. Times Higher Education (Supplement), 21.

Cooper, C. L., Sloan, S. J., \& Williams, S. (1998). Occupational stress indicator management guide. Windsor, United Kingdom: NFERNelson.

Costa, P. T., Jr., \& McCrae, R. R. (1992). NEO-PI-R: Professional manual. Odessa, FL: Psychological Assessment Resources.

Council of Labor Affairs, Executive Yuan, Taiwan. (2010). Labor statistics. Retrieved from: http://win.dgbas.gov.tw/dgbas04/bc5/earning/ ht456.asp

Demerouti, E., Blanc, P. M. L., Bakker, A. B., Schaufeli, W. B., \& Hox, J. (2009). Present but sick: A three-wave study on job demands, presenteeism and burnout. Career Development International, 14, 50-68. doi:10.1108/13620430910933574

Dew, K., Keefe, V., \& Small, K. (2005). Choosing to work when sick: Workplace presenteeism. Social Science and Medicine, 60, 2273-2282.

Elstad, J. I., \& Vabo, M. (2008). Job stress, sickness absence and sickness presenteeism in Nordic elderly care. Scand Journal of Public Health, 36 , 467-474. doi:10.1177/1403494808089557

Eysenck, H. J. (1990). Biological dimensions of personality. In L. A. Pervin (Ed.), Handbook of personality: Theory and research (pp. 244 276). New York, NY: Guilford Press.

Hair, J. F., Black, W. C., Babin, B. J., Anderson, R. E., \& Tatham, R. L. (1998). Multivariate data analysis (Vol. 5). Englewood Cliffs, NJ: Prentice Hall.

Hansen, C. D., \& Andersen, J. H. (2008). Going ill to work: What personal circumstances, attitudes and work-related factors are associated with sickness presenteeism? Social Science and Medicine, 67, 956-964. doi:10.1016/j.socscimed.2008.05.022

Hinkin, T. R. (1995). A review of scale development practices in the study of organizations. Journal of Management, 21, 967-988. doi:10.1177/ 014920639502100509

Jex, S. M., Bliese, P. D., Buzzell, S., \& Primeau, J. (2001). The impact of self-efficacy on stressor-strain relations: Coping style as an explanatory mechanism. Journal of Applied Psychology, 86, 401-409. doi:10.1037/ 0021-9010.86.3.401

Johns, G. (2010). Presenteeism in the workplace: A review and research agenda. Journal of Organizational Behavior, 31, 519-542. doi:10.1002/ job.630

Johns, G. (2011). Attendance dynamics at work: The antecedents and correlates of presenteeism, absenteeism, and productivity loss. Journal of Occupational Health Psychology, 16, 483-500. doi:10.1037/ a 0025153

Johns, G. (2012). Presenteeism: A short history and a cautionary tale. In J. Houdmont, S. Leka, \& R. Sinclair (Eds.), Contemporary occupational health psychology: Global perspectives on research and practice (Vol. 2, pp. 204-220). Malden, MA: John Wiley \& Sons.

Lahey, B. B. (2009). Public Health significance of neuroticism. American Psychologist, 64, 241-256. doi:10.1037/a0015309

Lazarus, R. S., \& Folkman, S. (1984). Stress, appraisal and coping. New York, NY: Springer.

Levin-Epstein, J. (2005). Presenteeism and paid sick days. Center for Law and Social Policy, 1-4.

Löve, J., Grimby-Ekman, A., Eklöf, M., Hagberg, M., \& Dellve, L. (2010). Pushing oneself too hard: Performance-based self-esteem as a predictor of sickness presenteeism among young adult women and men-a cohort study. Journal of Environment Medicine, 52, 603-609. doi:10.1097/ JOM.0b013e3181dce181

Lu, L. (2011). Working hours and personal preference among Taiwanese employees. International Journal of Workplace Health Management, 4, 244-256. doi:10.1108/17538351111172608 
Lu, L., Chang, Y. Y., \& Lai, S. Y. L. (2011). What differentiates success from strain: The moderating effects of self-efficacy. International Journal of Stress Management, 18, 396-412. doi:10.1037/a0025122

Lu, L., Kao, S. F., Cooper, C. L., Allen, T. D., Lapierre, L. M., O’Driscoll, M., . . . Spector, P. E. (2009). Work resources, work-to-family conflict, and its consequences: A Taiwanese-British cross-cultural comparison. International Journal of Stress Management, 16, 25-44. doi:10.1037/ a0013988

Lu, L., Kao, S. F., Siu, O. L., \& Lu, C. Q. (2011). Work stress, Chinese work values, and work well-being in the Greater China. Journal of Social Psychology, 151, 767-783. doi:10.1080/00224545.2010.538760

Lu, L., Lee, H. M., \& Shieh, T. Y. (2005). Occupational stress, health and occupational burnout among dentists: A study of clinical dentists in Kaohsiung. Research in Applied Psychology, 27, 59-80.

Lu, L., Siu, O. L., \& Lu, C. Q. (2010). Does loyalty protect Chinese workers from stress? The role of affective organizational commitment in the Greater China region. Stress \& Health, 26, 161-168. doi:10.1002/ smi. 1286

Lu, L., Tseng, H. J., \& Cooper, C. L. (1999). Managerial stress, job satisfaction and health in Taiwan. Stress Medicine, 15, 53-64. doi: 10.1002/(SICI) 1099-1700(199901)15:1<53::AID-SMI790>3.0.CO;2-7

Maslach, C., \& Jackson, S. (1986). Maslach Burnout Inventory manual (2nd ed.). Palo Alto, CA: Consulting Psychologists Press.

Maslach, C., Schaufeli, W. B., \& Leiter, M. P. (2001). Job burnout. Annual Review of Psychology, 52, 397-422. doi:10.1146/annurev.psych.52.1 .397

Meijman, T. F., \& Mulder, G. (1998). Psychological aspects of workload. In P. J. D. Drenth \& H. Thierry (Eds.), Handbook of work and organizational psychology (Vol. 2, pp. 5-33). Hove, United Kingdom: Psychology Press.

Ministry of Economic Affairs, R. O. C. (2012). Statistics of economic. Retrieved from: http://www.moeasmea.gov.tw/lp.asp?ctNode $=689 \& \mathrm{Ct}$ Unit $=140 \&$ BaseDSD $=7 \& \mathrm{mp}=1$

Motowidlo, S. J., \& Van Scotter, J. R. (1994). Evidence that task performance should be distinguished from contextual performance. Journal of Applied Psychology, 79, 475-480. doi:10.1037/0021-9010.79.4.475

Podsakoff, P., MacKenzie, S., Lee, J., \& Podsakoff, N. (2003). Common method biases in behavioral research: A critical review of the literature and recommended remedies. Journal of Applied Psychology, 88, 879903. doi:10.1037/0021-9010.88.5.879
Robertson, I., \& Cooper, C. L. (2011). Well-being: Productivity and happiness at work. Hampshire, United Kingdom: Palgrave Macmillan.

Salanova, M., Peiro, J. M., \& Schaufeli, W. B. (2002). Self-efficacy specificity and burnout among information technology workers: An extension of the job demand-control model. European Journal of Work and Organizational Psychology, 11, 1-25. doi:10.1080/ 13594320143000735

Saucier, G. (1994). Mini-Markers: A brief version of Goldberg's Unipolar Big-Five Markers. Journal of Personality Assessment, 63, 506-516. doi:10.1207/s15327752jpa6303_8

Schaubroeck, J., Lam, S., \& Xie, J. L. (2000). Collective efficacy versus self-efficacy in coping responses to stressors and control: A crosscultural study. Journal of Applied Psychology, 85, 512-525. doi: 10.1037/0021-9010.85.4.512

Schaubroeck, J., \& Merritt, D. E. (1997). Divergent effects of job control on coping with work stressors: The key role of self-efficacy. Academy of Management Journal, 40, 738-754. doi:10.2307/257061

Schwarzer, R., Babler, J., Kwiatek, P., Schroder, K., \& Zhang, J. X. (1997). The assessment of optimistic self-beliefs: Comparison of the German, Spanish, and Chinese versions of the General Self-efficacy Scale. Applied Psychology: An International Review, 46, 69-88. doi:10.1111/j .1464-0597.1997.tb01096.x

Shirom, A. (2003). Job related burnout: A review. In J. C. Quick \& L. E. Tetrick (Eds.), Handbook of occupational health psychology (pp. 245264). Washington, DC: APA. doi:10.1037/10474-012

Turpin, R. S., Ozminkowski, R. J., Sharda, C. E., Collins, J. J., Berger, M. L., Billotti, G. M., \& Nicholson, S. (2004). Reliability and validity of the Stanford Presenteeism Scale. Journal of Occupational and Environmental Medicine, 46, 1123-1133. doi:10.1097/01.jom.0000144999 $.35675 . \mathrm{a} 0$

Wu, H. P., Lu, L., Ku, C. C., \& Chang, Y. Y. (2010). The associations between transformational leadership behaviors and subordinates' work stress and supervisor satisfaction. Chung Hua Journal of Management, 11, 1-30.

Received October 14, 2012 Revision received August 6, 2013 Accepted August 9, 2013

\section{E-Mail Notification of Your Latest Issue Online!}

Would you like to know when the next issue of your favorite APA journal will be available online? This service is now available to you. Sign up at http://notify.apa.org/ and you will be notified by e-mail when issues of interest to you become available! 